Sādhanā Vol. 40, Part 2, April 2015, pp. 537-547. (C) Indian Academy of Sciences

\title{
An experiment-based comparative investigation of correlations for microtube gas flow
}

\author{
K TANG，J L HUANG，T JIN* and M X WU \\ State Key Laboratory of Clean Energy Utilization, Department of Energy \\ Engineering, Zhejiang University, Hangzhou 310027, P.R. China \\ e-mail: jintao@zju.edu.cn
}

MS received 12 January 2014; revised 01 September 2014; accepted 06 November 2014

\begin{abstract}
An experimental system was built to measure the gas (nitrogen and helium) flow characteristics in circular microchannels with diameters of 50, 20 and 5 $\mu \mathrm{m}$. The Reynolds number of the flow was controlled in the large range of 15 to 2550 . The highest Mach number could reach a magnitude of 0.625 and the highest Knudsen number was over 0.021 . Four available empirical correlations were comparatively studied, in terms of the influence from compressibility and rarefaction. The accuracy of each correlation was investigated, and qualitative explanations were given according to the essence of fluid dynamics. The compressibility is found to be the dominant parameter in the experiments carried out. The results obtained by gas flow in holey optical fibres are helpful for the design of micro-scale pulse tube cryocoolers.
\end{abstract}

Keywords. Flow characteristics; correlation; microtube; pulse tube cryocooler.

\section{Introduction}

With the rapid development of microelectromechanical systems (MEMS) and microflow devices (MFD) in the recent decades, the accurate predictions of fluid dynamics and heat transfer phenomena of microfluids are of great significance in the design, manufacture and operation of these systems. For example, a micro-scale pulse tube cryocooler (PTC) based on holey optical fibres has been proposed and modelled (Jin et al 2013). The holey fibre used as flow channel was described as the non-metal pipe bundle and introduced as the regenerator (the core device of thermoacoustic related machines) for PTCs. The thermal performance with optical fibres as the regenerator has been analysed for the potential application in the miniaturization of cryocoolers. Besides, the flow resistance in holey optical fibres is also vital for the design of micro PTCs.

However, no perfectly unified model has been setup, leading to the fact that there is no universal approach and conclusion to a variety of problems (Agrawal 2011). Meanwhile, the validity of the experimental data from relatively complex microflow systems is rigorously restricted by the

${ }^{*}$ For correspondence 
measurement techniques for analysis (Morini et al 2011). As a result, the empirical correlations given by different researchers are basically confined to the corresponding specific situations.

Compressibility, rarefaction and surface roughness are considered as the key factors that can bring about the microflow deviations from the conventional tube flows (Kandlikar et al 2006). Correspondingly, the non-dimensional parameters of Mach number, Knudsen number and relative roughness have been introduced to characterize their influences, which are defined as follows.

$$
\begin{gathered}
M a=\frac{V}{a}, \\
K n=\frac{\lambda}{L}, \\
r=\frac{\varepsilon}{D_{\mathrm{h}}},
\end{gathered}
$$

where $V$ is the velocity of the fluid, $a$ is the sound speed of the fluid, $\lambda$ is the mean free path of the fluid molecules, $L$ is the characteristic length, $\varepsilon$ is the absolute roughness, and $D_{\mathrm{h}}$ is the hydraulic diameter.

Theoretical and experimental studies on the microflow pressure drop and Darcy frictional factors (Ergu et al 2009; Hooman et al 2009; Verma et al 2009), taking the compressibility, rarefaction and relative roughness into consideration have been presented in literature. Many novel ideas have also been introduced to this field (Salimpour et al 2011; Choi \& Kim 2011).

Asako et al (2005) have expressed the product of Darcy friction factor and Reynolds number (i.e., Poiseuille number) as a function of Mach number. A Poiseuille number correlation, as Eq. (4), was obtained from the numerical results for $M a<0.4$.

$$
P o=f \cdot R e=64-11.99 M a+263.7 M a^{2} .
$$

Hong et al (2009) have solved the two-dimensional compressible momentum and energy equations with both non-slip and slip boundary conditions for the gaseous flow in microtubes and obtained the Poiseuille number correlations for the high speed flow in the range of $R e<1800$ and $M a<0.6$.

In the case of non-slip flow regime, Poiseuille number is a function of Mach number and differs from the incompressible value of 64 for a circular tube, as given in Eq. (5),

$$
P o=f \cdot R e=64+5.62 M a+100.41 M a^{2}+254.14 M a^{3} .
$$

In the case of slip flow regime, Poiseuille number is a function of the Mach number and Knudsen number, as shown in Eq. (6),

$$
P o=f \cdot R e=\frac{64}{1+8 K n}+\frac{5.62 M a+100.41 M a^{2}+254.14 M a^{3}}{(1+8 K n)^{2}} .
$$

Turner (2003) has considered the rarefaction effect due to low Reynolds number and low Mach number conditions. The relationship among $f, K n$ and $\alpha$ was obtained by the curve-fitting from experimental data, where $\alpha$ is the fraction of the molecules that strike the wall of microchannel and reflect at a random angle, hence it is also called tangential momentum accommodation coefficient, which ranges from 0.35 to 0.75 for low roughness flow. The expression is given below (Turner 2003),

$$
\frac{f}{f_{\text {theory }}}=\frac{1}{1+6\left(\frac{2-\alpha}{\alpha}\right) K n} \text {. }
$$


In this paper, the gas flow characteristics in the microtubes with three diameters were measured and the accuracy of each above-mentioned correlation was investigated. Nitrogen flow and helium flow were tested in our experiments, in order to achieve larger ranges of the Knudsen number and Reynolds number. To test the accuracy of each correlation and to give the qualitative explanations according to the essence of fluid dynamics, the four available correlations mentioned above, i.e., Eqs. (4)-(7), were comparatively studied based on experimental data, in terms of the influence from compressibility and rarefaction. Meanwhile, the experiments obtained from gas flow in the holey optical fibres provide the flow resistance for the design of micro-scale pulse tube cryocoolers.

\section{Experimental set-up}

A test system was built to measure the flow characteristics in the microtubes made of fused silica. Here, micro-manufactured fused quartz tubes (50 and $20 \mu \mathrm{m}$ in diameter) and holey optical fibres ( $5 \mu \mathrm{m}$ in diameter) were both used as the test microtubes. The lengths of the tubes vary from 5.92 to $6.23 \mathrm{~cm}$, which is long enough for the flow to become fully developed. The schematic diagram of the test system is shown in figure 1. High-pressure gas flows out of the cylinder and passes the relieve valve, the filter, the mass flow rate meter and the test section in turn. The outlet pressure is regulated by a counterbalance valve. The temperature and pressure signals, collected by the sensors located at the test section, are treated by NI compact DAQ for monitoring and saving. The mass flow rate meter is Bronkhorst F-211CV with the largest control flow rate of $2.83 \times 10^{-6} \mathrm{~kg} / \mathrm{s}$ for nitrogen $(0.5 \% \mathrm{RD}+0.1 \% \mathrm{FS})$. Pressure sensors are GE Druck PM5074 ranging from 0 to $10 \mathrm{MPa}$ gauge pressure with the accuracy of $0.2 \%$ FS. Temperature sensors are Chino PT100 platinum resistance thermometer ranging from 0 to $350^{\circ} \mathrm{C}$ with the internal errors of $\pm 0.35^{\circ} \mathrm{C}$.

The thermometers and pressure sensors were fabricated in the inlet and outlet chambers for the measurement of temperature and pressure, respectively. The tested microtube was put into the casing stainless steel pipe. Its junction parts were carefully smeared with 504 glue to ensure

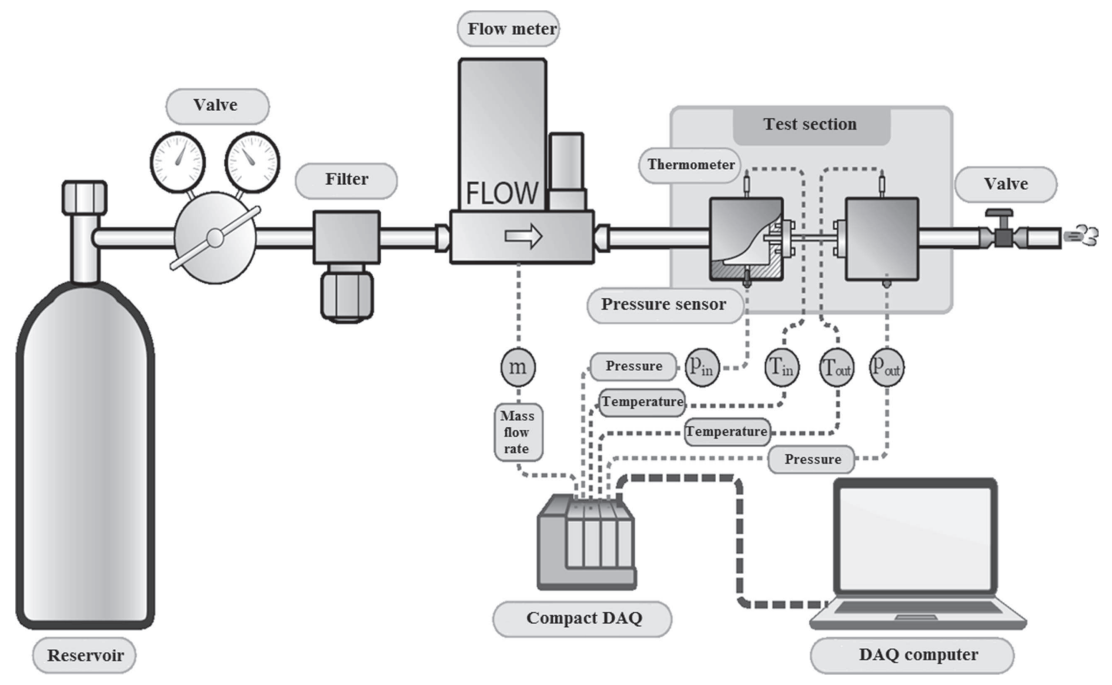

Figure 1. Schematic diagram of test system. 
no gas leak in the test section. Also, rubber O-rings were placed in the test section for proper sealing.

Before measurements, leakage detection was done by means of coating the piping connections with soap and water with no evident leakage point observed. Each time before running, the system was charged with gas to the pressure of over $1 \mathrm{MPa}$. The experiment was allowed to be carried out, if no observable change was detected by the pressure sensor after 24 hours. That is to say that the leakage value is within $1 \%$ per day. As the time scale for each test would be within several hours, the sealing technique used in the set-up would cause no influence on the experimental data. The leakage of the system is negligible.

\section{Results and discussion}

The following equation can be derived from the definition of Reynolds number for the fluid in a circular channel,

$$
R e=\frac{\dot{m} D}{A \mu},
$$

from which the $f$-Re diagram can be drawn, by adjusting the mass flow rate, for summarizing the experimental data. In Eq. (8), $A$ is the cross-sectional area of the tube and $\mu$ is the viscosity of the fluid. It should be noted that the mass flow rate is a controlled parameter during the experiments, which makes it easy to achieve the adjustment of Reynolds number. In our experiments, with slight temperature change, the Reynolds number was assumed constant according to negligible change of viscosity.

According to Eq. (8), for certain working fluid in determined flow geometry, Reynolds number is proportional to the mass flow rate. The mass flow rate can be easily calculated, given the Reynolds number, tube diameter and viscosity of the fluid. A certain Reynolds number implies the corresponding mass flow rate for each case in the experiment.

For the calculation of the Mach number which has been defined in Eq. (1), the average Mach number for data analysis was obtained by the method of Asako et al (2005), where the velocity, pressure and density information obtained were linearly averaged. It is also important to note that $K n$ can be roughly estimated in terms of Reynolds number and Mach number (Croce \& Agaro 2009)

$$
K n=\sqrt{\frac{\gamma \pi}{2}} \frac{M a}{R e},
$$

where $\gamma$ is the specific heat ratio of the fluid.

For the measurements of flow characteristics, the data are usually presented in the form of Poiseuille number versus Reynolds number, where the Poiseuille number is the product of Darcy friction factor and Reynolds number (Dutkowski 2008; Celata et al 2007). Shapiro (1953) has proposed an equation to calculate the friction factor for compressible flow as follows,

$$
f=\frac{D_{\mathrm{h}}}{L}\left[\left(\frac{1-\left(1-\frac{\Delta p_{\mathrm{n}}}{p_{\mathrm{i}}}\right)^{2}}{\left(\frac{\dot{m} \sqrt{R T}}{A p_{\mathrm{i}}}\right)^{2}}-2 \ln \left(\frac{1}{1-\frac{\Delta p_{\mathrm{n}}}{p_{\mathrm{i}}}}\right)\right],\right.
$$

where $\Delta p_{\mathrm{n}}$ is the pressure drop along the microchannel, $\dot{m}$ is the mass flow rate, $R$ is the gas constant, $T$ is the temperature of the fluid, $p_{\mathrm{i}}$ is the inlet pressure.

As reported by earlier works (Celata et al 2007; Ergu et al 2009), the flow-development lengths in the experiments are still minor when compared to the whole lengths. The microtube 
lengths in this work are remarkably larger compared to the work mentioned above, so it is reasonable to consider the flow as fully developed in the test process. The development length is within the $1 \%$ of the whole length, i.e., in this case, the value of flow development length is between 0.5 and $0.8 \mathrm{~mm}$.

Firstly, the flow characteristics in the $50 \mu \mathrm{m}$ capillaries of different lengths were tested to validate the experimental facility and measurement method. The plot of basic pressure drop versus mass flow rate for nitrogen flow in $50 \mu \mathrm{m}$ microtube is shown in figure 2 (test section length $7.80 \mathrm{~cm}$ ). Figures 3 and 4 show the Darcy friction factor versus Reynolds number in $50 \mu \mathrm{m}$ capillaries with length of 5.00 and $7.80 \mathrm{~cm}$, which shares similar variation trend with Moody's diagram (Granger 1995). However, in the light of compressibility, data in figures (3) and (4) deviate from those in Moody's diagram. The details can be referred to in our previous work (Jin et al 2012).

The experimental data from the fully developed flow in conventional channels indicate that Darcy friction factor versus Reynolds number is not a function of tube geometries, such as diameter and length. This phenomenon can also be observed by the results presented in figures 3 and 4 . When it comes to micro scale, the rarefaction starts to affect the flow characteristics in the tubes. Along with the effect of compressibility, the Poiseuille number of the flow will deviate from the conventional value, which is evident in the following analyses.

Figure 5 presents the test results for the nitrogen flow inside the $50 \mu \mathrm{m}$ diameter microtube in a large range of Reynolds numbers from laminar to transition regime, and in a range of largest Knudsen numbers from conventional flow to slip flow regime. For the Reynolds numbers ranging from 470 to 2550 with the average Mach numbers from 0.102 to 0.625 , estimated largest Knudsen number 0.00033, the Poiseuille number rises significantly. The experimental errors lower than $\pm 7.7 \%$ are indicated by the error bar.

The results calculated from Eqs. (4), (5), (6) and (7) are also shown in figure 5 for comparison. We can find that the slip flow correlation (Eq. (6)) given by Hong et al (2009) presents the best prediction in the large ranges of both Reynolds number and Knudsen number. As Reynolds number is proportional to the mass flow rate, a larger Reynolds number indicates a higher gas flow velocity in the given cross section area. As a matter of fact, a larger Mach number, defined

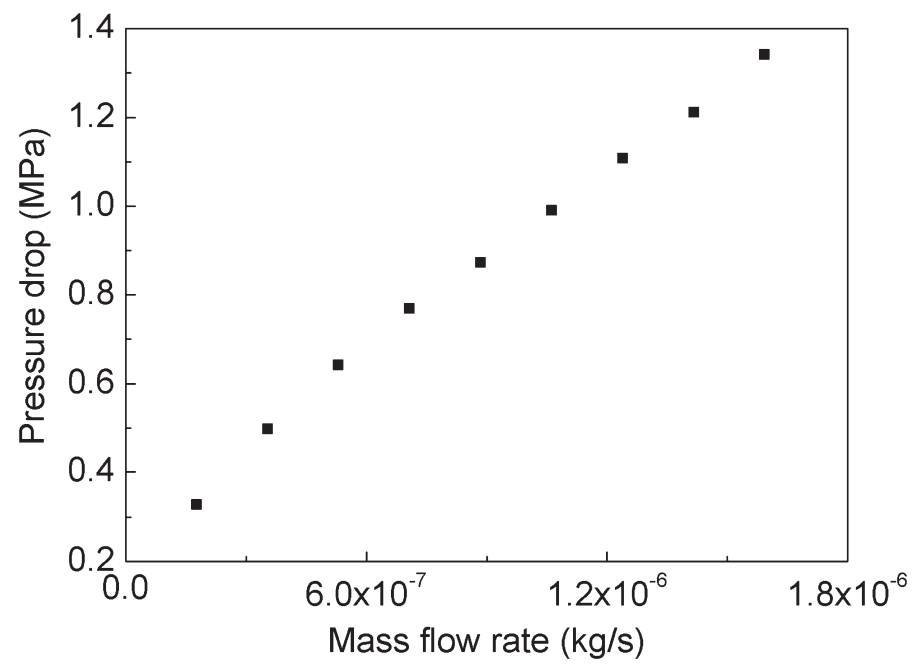

Figure 2. Pressure drop versus mass flow rate of nitrogen flow in $50 \mu \mathrm{m}$ diameter microtube, $7.80 \mathrm{~cm}$ in length $(0.102 \leq M a \leq 0.625, K n \cong 0.00033)$. 


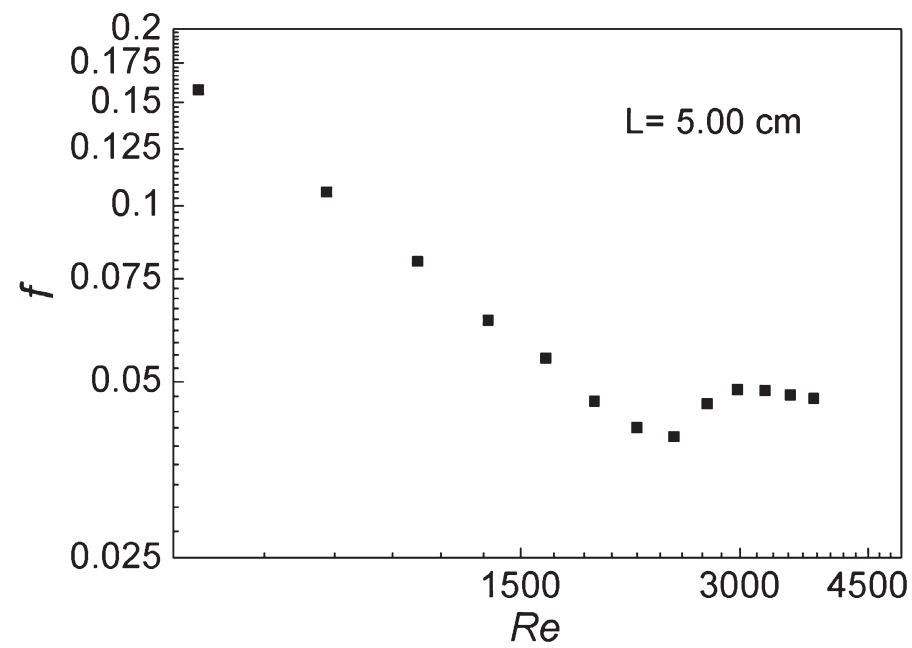

Figure 3. Friction factors dependency on $R e$ of nitrogen flow in $50 \mu \mathrm{m}$ diameter microtube with length of $5.00 \mathrm{~cm}(0.102 \leq M a \leq 0.625, \mathrm{Kn} \cong 0.00033)$.

as the flow velocity divided by the speed of sound, can be achieved. Therefore, larger deviation with the rising Reynolds number is the result of increasing Mach number. The average Mach number exceeds the upper limit of 0.4 for Eq. (4) (as large as 0.625).

The empirical correlations of Eqs. (4) and (5) given by Asako et al (2005) and Hong et al (2009), which merely considered the influence of compressibility on Poiseuille number, can also reflect the variation trend of $P o$. This indicated that the compressibility is the dominant factor in the microtube flows, and the empirical correlations focusing on Mach number can roughly predict the whole range of the flow regime in this case.

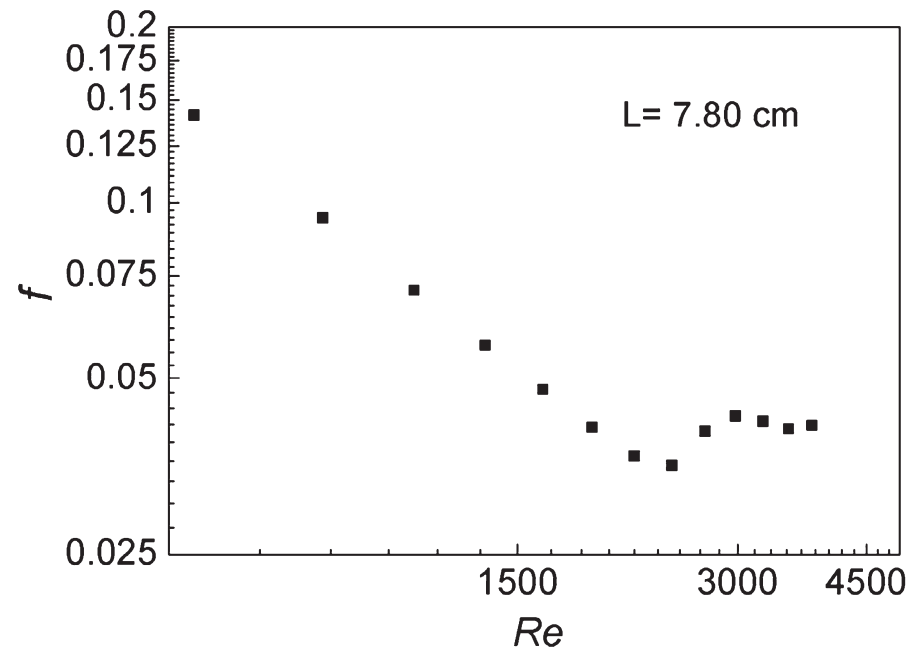

Figure 4. Friction factors dependency on $R e$ of nitrogen flow in $50 \mu \mathrm{m}$ diameter microtube with length of $7.80 \mathrm{~cm}(0.102 \leq M a \leq 0.625, K n \cong 0.00033)$. 


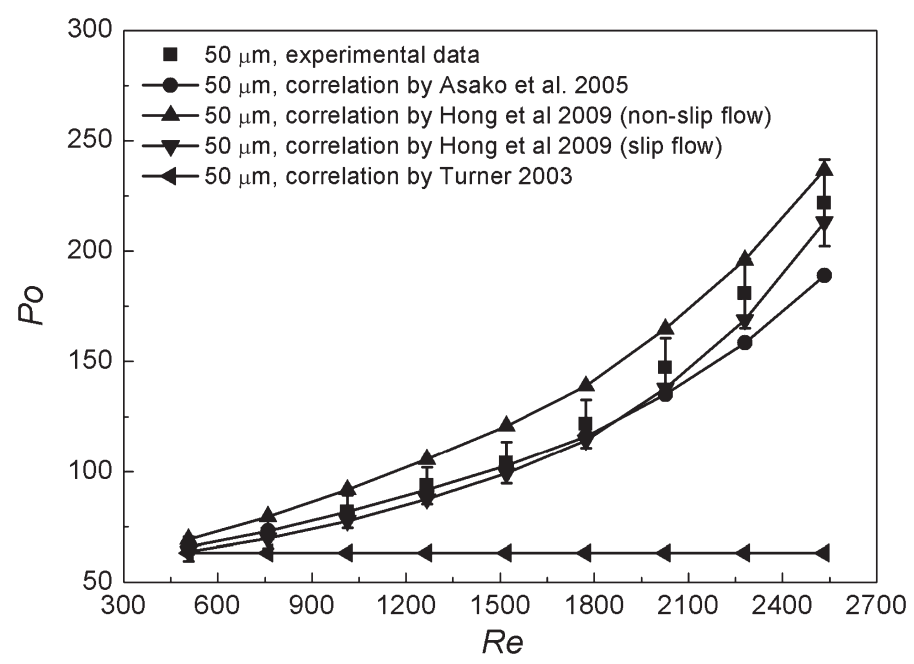

Figure 5. Po dependency on $R e$ of nitrogen flow in $50 \mu \mathrm{m}$ diameter microtube, compared with the available empirical correlations $(0.102 \leq M a \leq 0.625, K n \cong 0.00033)$.

Figure 6 shows the results of the nitrogen flow in the $20 \mu \mathrm{m}$ diameter microtube with low Reynolds numbers ranging from 165 to 335 (also indicating the average Mach numbers from 0.071 to 0.196 and the largest Knudsen number 0.00085). At the low Mach number flows, the rarefaction turns to be the leading factor, making Turner's equation (Turner 2003) to fit well with the experimental data, while the correlations with Mach number (Asako et al 2005; Hong et al 2009) are typically invalid.

The Poiseuille numbers of helium flow in the microtubes of 50, 20 and $5 \mu \mathrm{m}$ in diameter with low Reynolds number were measured, and then compared with empirical correlations as given in

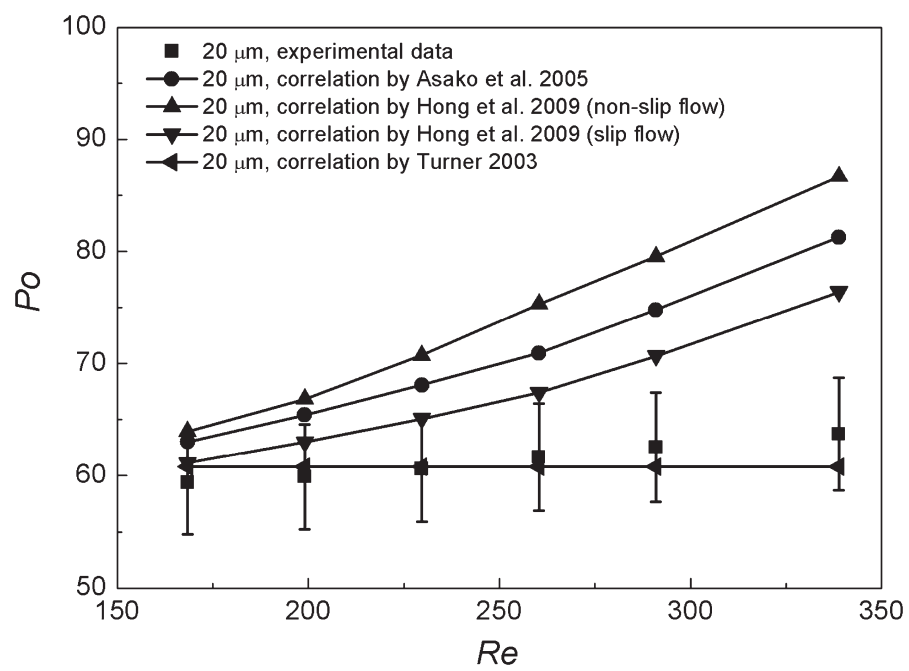

Figure 6. Po dependency on $R e$ of nitrogen flow in $20 \mu \mathrm{m}$ diameter microtube, compared with the available empirical correlations $(0.071 \leq M a \leq 0.196, K n \cong 0.00085)$. 


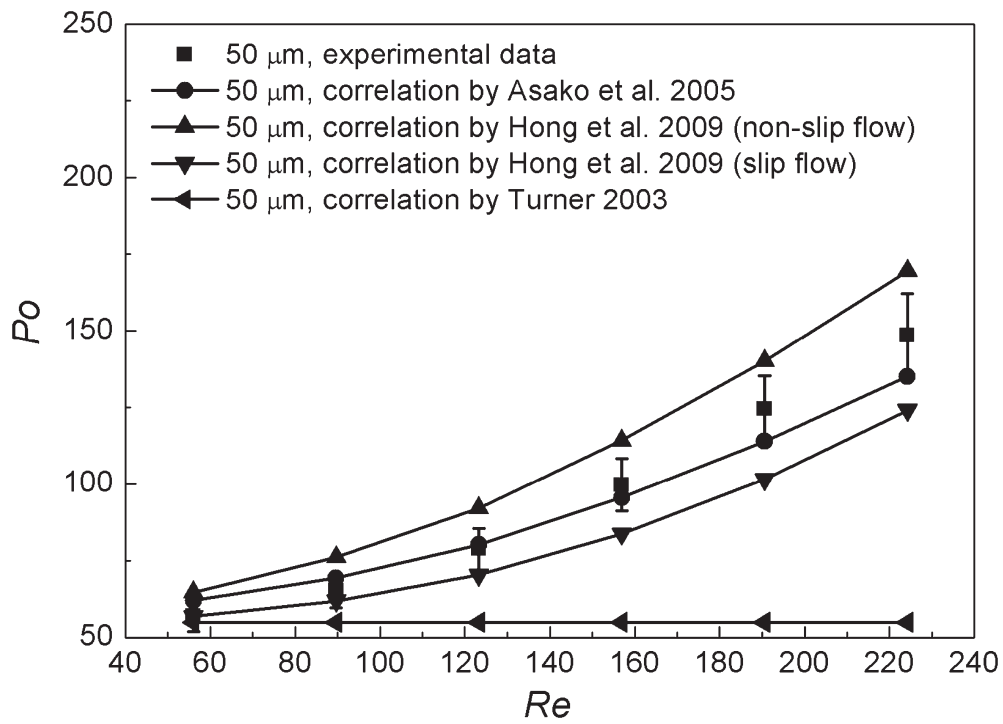

Figure 7. Po dependency on $R e$ of helium flow in $50 \mu \mathrm{m}$ diameter microtube, compared with the available empirical correlations $(0.113 \leq \mathrm{Ma} \leq 0.468, K n \cong 0.0034)$.

figures 7, 8 and 9, respectively. As we can see in the figures, Poiseuille number significantly rises with the increased Reynolds number, indicating that the compressibility is the dominant factor. Relatively high Mach numbers in the range from 0.113 to 0.604 are achieved, while the Reynolds numbers are kept comparatively low, thanks to the much lower density of helium gas. Thus, Eqs. (4), (5) and (6) can all reflect the variation trend of the increasing Po with the Reynolds number.

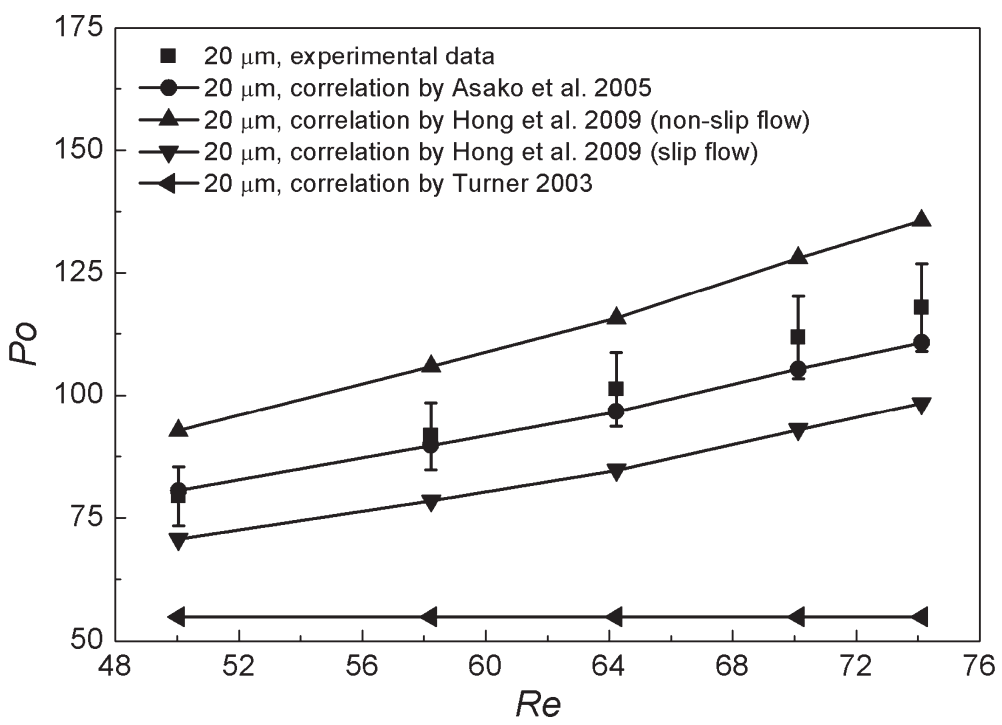

Figure 8. Po dependency on Re of helium flow in $20 \mu \mathrm{m}$ diameter microtube compared with the available empirical correlations $(0.278 \leq \mathrm{Ma} \leq 0.415, \mathrm{Kn} \cong 0.0091)$. 


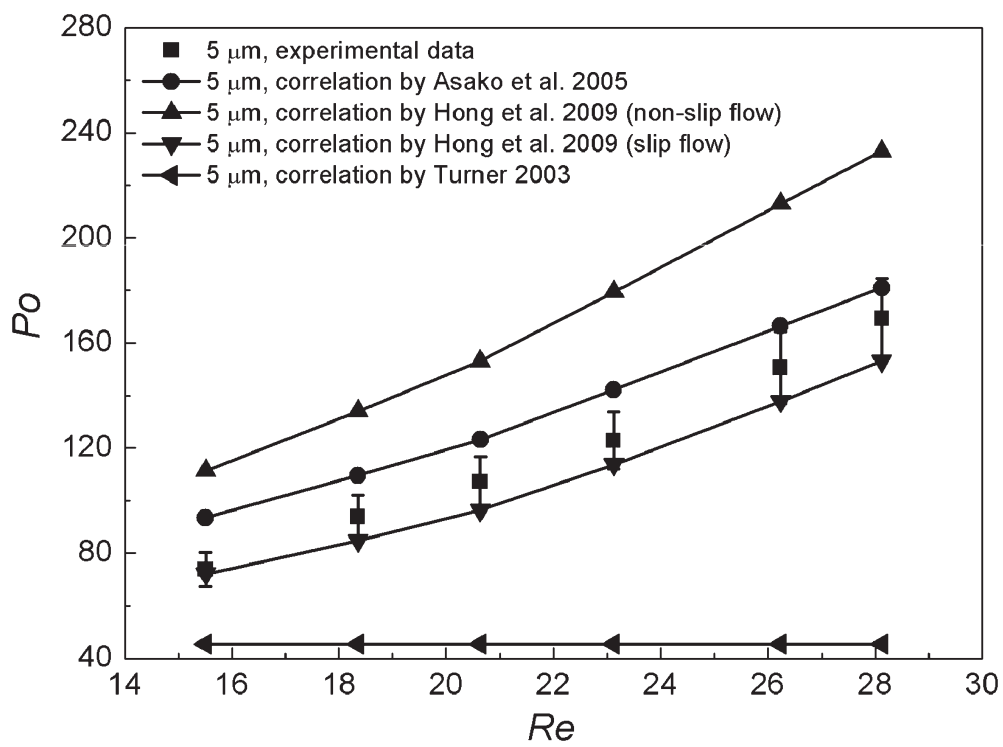

Figure 9. Po dependency on $R e$ of helium flow in $5 \mu \mathrm{m}$ diameter microtube, compared with the available empirical correlations $(0.324 \leq \mathrm{Ma} \leq 0.604, K n \cong 0.021)$.

Meanwhile, with the reduction of microtube diameter (i.e., the increase of the Knudsen number), the experimental data of $P o$ also tend to drop. As a result, the correlation including Mach number and Knudsen number, i.e., the Eq. (6) obtained by Hong et al (2009) with a slip flow condition, can fit well with the experiments for the microtube of $5 \mu \mathrm{m}$ in diameter, as shown in figure 9. In this case, a largest Knudsen number as high as 0.021 of the flow in the $5 \mu \mathrm{m}$ diameter microtube allows the rarefaction and the compressibility to compete at the same time.

\section{Conclusions}

An experimental system was built to measure the gas (nitrogen and helium) flow characteristics in the microtubes with diameters of 50, 20 and $5 \mu \mathrm{m}$, respectively. The Reynolds numbers of the flow were controlled between 15 and 2550, leading to the Mach numbers from 0.071 to 0.625 . The largest outlet Knudsen number reached a magnitude of 0.021 . The experiments focused on the Poiseuille number with respect to compressibility and rarefaction. The test results indicate that in our experiment ranges, $P o$ varies with the influence of compressibility and rarefaction, and that an increase in $M a$ leads to a rise in $P o$ and an increase in $K n$ leads to a drop in Po.

Four available empirical correlations were investigated in terms of the influence of compressibility and rarefaction. The compressibility is the dominant factor in the high speed microtube flows, for which the correlations with respect to $M a$, i.e., Eqs. (4), (5) and (6), can reflect the variation of $P o$. The effect of rarefaction needs to be considered for the low speed flows in small diameter microtubes with relatively low $M a$ and high $K n$. The correlations applicable to wider ranges of $M a$ and $K n$ with higher accuracy will be focused in the future work.

For the gas flow measurement in micro-scale holey optical fibres, the quantified flow resistance has been obtained, which is vital for the design and manufacture of micro PTCs using the optical fibres as its regenerator. 


\section{Acknowledgements}

This work was financially supported by the National Natural Science Foundation of China (51276154, 51076137) and the University Doctoral Subject Special Foundation of China (20100101110034).

\section{List of symbols}

\section{Latin}

$a$ sound speed of the fluid

$A$ cross-sectional area

$D$ diameter

$L$ characteristic length

$\dot{m}$ mass flow rate

$p$ pressure

$R$ gas constant

$T$ temperature

$V$ velocity

\section{Greek}

$\varepsilon$ absolute roughness

$\gamma$ specific heat ratio

$\lambda$ mean free path

$\mu$ viscosity

\section{Superscript and subscript}

h hydraulic

$i$ inlet

o outlet

theory theory predicted

\section{Abbreviation}

$K n$ Knudsen number

Ma Mach number

$P o$ Poiseuille number

Re Reynolds number

\section{References}

Agrawal A 2011 A comprehensive review on gas flow in microchannels. Int. J. Micro-Nano Scale Transp. 2(1): $1-40$

Asako Y, Nakayama K and Shinozuka T 2005 Effect of compressibility on gaseous flows in a microtube. Int. J. Heat Mass Trans. 48(23-24): 4985-4994

Celata G P, Cumo M, McPhail S J, Tesfagabir L and Zummo G 2007 Experimental study on compressible flow in microtubes. Int. J. Heat Fluid Fl 28(1): 28-36 
Choi C and Kim M 2011 Flow pattern based correlations of two-phase pressure drop in rectangular microchannels. Int. J. Heat Fluid Fl 32(6): 1199-1207

Croce G and Agaro P D 2009 Compressibility and rarefaction effect on heat transfer in rough microchannels. Int. J. Therm. Sci. 48(2): 252-260

Dutkowski K 2008 Experimental investigations of Poiseuille number laminar flow of water and air in minichannels. Int. J. Heat Mass Trans. 51(25-26): 5983-5990

Ergu O B, Sara O N, Yapici S and Arzutug M E 2009 Pressure drop and point mass transfer in a rectangular microchannel. Int. Commun. Heat Mass 36(6): 618-623

Granger R A 1995 Fluid mechanics. USA: Dover Publications

Hong C, Asako Y, Faghri M and Lee J H 2009 Poiseuille number correlations for gas slip flow in microtube. Numer. Heat Trans. A-Appl. 56(10): 785-806

Hooman K, Hooman F and Famouri M 2009 Scaling effects for flow in micro-channels: variable property, viscous heating, velocity slip, and temperature jump. Int. Commun. Heat Mass 36(2): 192-196

Jin T, Huang J L and Tang K 2012 Preliminary study on a novel pulse tube cryocooler based on optical fibre. Proceedings of the $24^{\text {th }}$ International Cryogenic Engineering Conference and International Cryogenic Materials Conference, Fukuoka, Japan. Cryogenic and Superconductivity Society of Japan, p. 333-338

Jin T, Huang J L, Tang K and Wu M X 2013 Performance analysis of a micro-scale pulse tube cryocooler based on optical fibre regenerator. Cryogenics 55-56: 30-34

Kandlikar S G, Garimella S, Li D, Colin S and King M R 2006 Heat transfer and fluid flow in minichannels and microchannels. Kidlington, Oxford: Elsevier

Morini G L, Yang Y, Chalabi H and Lorenzini M 2011 A critical review of the measurement techniques for the analysis of gas microflows through microchannels. Exp. Therm. Fluid Sci. 35(6): 849-865

Salimpour M R, Sharifhasan M and Shirani E 2011 Constructal optimization of the geometry of an array of micro-channels. Int. Commun. Heat Mass 38(1): 93-99

Shapiro A K 1953 The Dynamics and Thermodynamics of Compressible Fluid Flow. New York: John Wiley

Turner S E 2003 Gas Flow and Heat Transfer in Microchannels: An experimental investigation of compressibility, rarefaction and surface roughness. Ph.D. Thesis, University of Rhode Islan, Kingston, USA

Verma B, Demsis A, Agrawal A and Prabhu S V 2009 Semiempirical correlation for the friction factor of gas flowing through smooth microtubes. J. Vac. Sci. Technol. A 27(3): 584-590 